\title{
Controlling Workers' Compensation Costs In Construction
}

\author{
Prof. Neil Opfer, University of Nevada, Las Vegas
}

UNLV Associate Professor Department of Civil \& Environmental Engineering \& Construction

\section{Dr. David R. Shields P.E., University of Nevada, Las Vegas}

David R. Shields, Ph.D., P.E. Dr. Shields is an Associate Professor in Department of Civil and Environmental Engineering and Construction in the Howard R. Hughes College of Engineering at the University of Nevada, Las Vegas. He has received two outstanding faculty awards and two service awards at UNLV. He has over 25 years of industry and government experience in construction, engineering, and research and eight years of academic experience. He was Co-Chair of the ASCE Civil Engineering in the Oceans $\mathrm{V}$ conference. He was the only manager in the 55-year history of the Naval Civil Engineering Laboratory ever to win the Employee-of-the-Year Award. He has won numerous awards for project management. He has conducted research for the Construction Industry Institute, Center for Construction Industry Studies, U.S. Navy, U.S. Army, OSHA and other organizations. He has published 45 journal and conference papers. He holds a Ph.D. in Civil Engineering from the University of Texas at Austin and the M.S. and B.S. in Ocean Engineering from Texas A\&M University. 


\section{Controlling Workers Compensation Costs In Construction}

Introduction

Worker's compensation costs in U.S. construction are a significant cost element. These costs for certain crafts in certain states can exceed $\$ 50$ for every $\$ 100$ of base labor costs. Worker's compensation costs have a strong tie to medical costs which have recently outpaced general inflation levels in the U.S. economy. This, in turn, has obviously led to increased costs for contractors. However, in discussions by the authors with those in the construction industry, a number of proven strategies have been found which can significantly lower these compensation costs. Some contractors have just taken compensation costs as a given cost factor. Proactive contractors instead have taken a multi-faceted cost-reduction approach. Effective safety and safety training programs obviously reduce exposures in the first instance. Screening of prospective employees through substance-abuse testing has been seen to yield substantial benefits. These proactive contractors take this further by screening their prospective subcontractors and third-tier subcontractors for lower experience modification ratings (EMR). Moreover, they encourage project owners to set EMR targets at better-than industry-average numbers to screen out unsafe contractors in the bidding competition for projects. These steps reduce multiemployer work-site issues. Knowledgeable owners will accept EMR specification requirements in order to reduce chances for third-party lawsuits and associated issues. Owners such as state DOT units have encouraged additional safety procedures in work zone safety by paying for such items as safety signs and barricades on a unit-price basis thereby discouraging contractors from cutting corners in these areas. Other owners have provided direct compensation for job-specific safety training. Constructability analysis to reduce safety exposure through increased pre-fab work and pre-assembly at ground level were some techniques found to provide a safer work environment. This ground-level work means fewer hours for personnel at height where fall risks are present. Proactive contractors have incorporated safety performance along with productivity, cost, and quality targets in their evaluation and promotion criteria. First-line and second-line supervision should be trained to understand both the direct and indirect costs of accidents along with the impact of supervision on EMR numbers.

State laws in option states allow contractors increased flexibility to seek premium reductions including risk pooling and self-insurance choices. In addition, contractors can implement techniques including audit procedures, fraud investigation, and effective classification analysis to reduce costs. Contractors operating under consolidated insurance programs on projects such as entity-controlled insurance programs (ECIP) can see substantial reductions when including worker's compensation insurance. The introduction of ECIPs means a unified safety program. Part of this can include mandated safety training with upfront costs paid for by overall insurance program savings. Key benefits of the ECIP whether residing with the owner or overall general contractor are economies of scale, certainty of coverage, and administrative benefits.

In discussions with the construction industry, contractors in the same business lines who implemented the above items on a systematic basis experienced premium savings of $30 \%$ or more on some projects as compared to their competitors. Construction education needs to 
include information on cost containment strategies since issues in this area are an increasingly important component of the construction business.

Academic locations for this information would include coursework in construction estimating, construction management, and construction business operation classes. While construction safety classes are traditionally geared towards safety standards/regulations along with compliance methods/equipment issues, discussion of sound safety practices and their EMR impacts should be noted to students. Enhanced job-site construction safety is important from a humanitarian and legal standpoint but also should be noted to construction students from an economic standpoint.

Worker's Compensation Cost Containments' Place In Construction Education Construction curricula vary widely across the country in terms of both courses and the actual content of these courses. However, somewhere in this mix is a coverage of topics in the estimating and management area. Construction projects uniformly involve construction labor and its associated costs. Worker's compensation premiums are a key part of these labor costs. The widely-used R.S. Means Building Construction Cost Data Book notes, as an example, that worker's compensation rates for California range from a low of $\$ 5.07$ for an elevator constructor to a high of $\$ 71.13$ for a roofer. ${ }^{13}$ This means that the roofing contractor is paying as a base or manual rate $\$ 71.13$ for premiums per $\$ 100$ of labor wages. The average of all trades in California is listed as $26.8 \%$ by R.S. Means. ${ }^{13}$ The $\$ 71.13$ would be for a contractor with an EMR number of 1.00 where this number represents the industry average. A contractor with an EMR at 0.80 would therefore pay $\$ 56.90$ per $\$ 100$ of payroll $(0.80 \times \$ 71.13=\$ 56.90)$. Professors teaching construction estimating can readily show the difference in bid pricing between the two contractors. A professor can readily show that the EMR- 0.80 contractor can spend $10 \%$ more on safety for the job (safety training, lifelines, fall protection, etc.) and still achieve a significant competitive advantage over the average of the industry. The author's past discussions with colleagues across the country involved in estimating education finds that, in the main, they emphasize achieving a competitive advantage in this estimating instruction through improved construction methods and improved productivity. Since contractors can also achieve a competitive advantage in this area with improved EMRs and other practices, this knowledge should find its way into construction coursework in the areas of estimating and other areas where appropriate.

For instance, these examples can be incorporated into construction coursework dealing with construction safety and project or firm management. The effectiveness of jobsite management with improved construction safety practices directly impacts these EMR numbers for a contractor. Construction students need to understand this impact. Common elements of construction safety education include regulatory coverage of OSHA requirements and other safety standards. Students should understand that safety is not only important from a humanitarian and legal standpoint but also from an economic standpoint. Unfortunately the authors have found in safety education that some students tend to tune this message out for a variety of reasons. This may be due to the culture in construction which tends to place all safety responsibility on the safety personnel or a general dislike of OSHA. In addition, workers' compensation costs are simply viewed as a given fixed part of labor burden. When these students see the impact of safety and 
the wide swings of EMR numbers between contractors, they tend to understand the impact of poor safety records and how they can positively influence this area.

The overarching goal of construction education is to improve industry practice through providing better-educated personnel for construction. Therefore educators should look for multiple opportunities to incorporate the information contained in this paper into their classes.

Note that while direct injury costs are covered by worker's compensation insurance, that the insurance carrier while modify upward the firm's premiums. One author illustrated in Table 1 (adapted) below that if costs went up by increments, how much more in additional revenue was required by the construction firm to compensate for these increased $\operatorname{costs}^{3}$ :

Table 1

\begin{tabular}{|l|l|l|l|l|l|}
\hline $\begin{array}{l}\text { Extra } \\
\text { Insurance } \\
\begin{array}{l}\text { Premiums } \\
\text { Due To Injury }\end{array}\end{array}$ & $\begin{array}{l}\text { Margin } \\
\text { Marofit }\end{array}$ & $\begin{array}{l}\text { 2\% Profit } \\
\text { Margin }\end{array}$ & $\begin{array}{l}3 \% \text { Profit } \\
\text { Margin }\end{array}$ & $\begin{array}{l}4 \% \text { Profit } \\
\text { Margin }\end{array}$ & $\begin{array}{l}5 \% \text { Profit } \\
\text { Margin }\end{array}$ \\
\hline$\$ 1000$ & $\$ 100,000$ & $\$ 50,000$ & $\$ 33,000$ & $\$ 25,000$ & $\$ 20,000$ \\
\hline$\$ 5000$ & $\$ 500,000$ & $\$ 250,000$ & $\$ 167,000$ & $\$ 125,000$ & $\$ 100,000$ \\
\hline$\$ 10,000$ & $\$ 1,000,000$ & $\$ 500,000$ & $\$ 333,000$ & $\$ 250,000$ & $\$ 200,000$ \\
\hline
\end{tabular}

This can serve as a powerful example to construction students of the impact to the firm from extra insurance costs over what the firm would pay with a better safety record.

\section{Contractor Demographics}

For the information in this paper, information was obtained from two sources. The first source was twenty-seven contractors that the authors have worked for over the past several years. Their approximate business contract volumes ranged from $\$ 3$ million to $\$ 120$ million per year. These contractors were split between approximately $62 \%$ in the industrial/heavy construction market and $38 \%$ in the non-residential building construction market. The smallest of these contractors were in the construction repairs/tenant build-out specialties. There were no residential-segment contractors in this group due to the severe housing downturn in the author's market area. The second source was from a few years ago in conjunction with consulting work for an insurance carrier. One of the authors performed a private research study of their contractor base. This study conducted in the 2009-2010 timeframe was with regards to worker's compensation premiums and associated contractor practices. ${ }^{2}$ The carrier wanted to ascertain best practices amongst their respective contractors in this area. These contractors were a mix of subcontractors and contractors from residential construction (28\%), non-residential building construction (28\%), and industrial/heavy construction (42\%) market segments. ${ }^{2}$ Contractor size in approximate terms ranged from a low of $\$ 5$ million in annual contract volume to a high of $\$ 384$ million. ${ }^{2}$ As in the first source, the smallest of these contractors were in the construction repairs/tenant build-out specialties. All contractors had been impacted by the 2008 recession with the most significant downturns in the residential and non-residential building sectors. The business volumes for residential/non-residential building were significantly less than at the peak of the housing and office building construction boom for this contractor sector. From both sources, it was found 
that contractors with volumes in excess of $\$ 50$ million had the best safety practices and associated worker's compensation practices. Smaller contractors $(<\$ 50$ million) had correspondingly poorer safety records. Smaller contractors $(<\$ 50$ million) typically had no one with full-time safety responsibilities and were contracting with trade associations or private vendors for periodic safety checks on jobsites. These smaller contractors also had the least knowledge of workers' compensation rates and potential differences.

\section{Worker's Compensation Cost Structure}

Worker's compensation rates vary widely from state to state based on that states' legislation and program administration. Different states pay out different amounts for the same type of injury to a worker. Worker's compensation premiums are paid based on payroll by the employer to the insurance entity. In some states this may be a state fund whereas in other states it is a private insurer. The rate for a particular work classification such as a carpenter or ironworker is referred to as the manual rate. From here the manual rate paid by the employer is adjusted up or down based on the particular employer's experience modification rating (EMR). The EMR is an adjustment to the manual rate based on prior year's losses for that contractor and the contractor's payroll compared to average claims paid out in that industry. The construction industry while having approximately $5 \%$ of the nation's workforce experiences $17 \%$ to $20 \%$ of its fatalities. ${ }^{1}$ A contractor with a safety record at the industry average will have an EMR of 1.00. If a contractor has a safety record better than the industry average in the particular classification, the EMR will be below 1.00. A safety record worse than the industry average will result in an EMR above 1.00. If an industry average contractor at 1.00 is paying $\$ 32$ per $\$ 100$ of payroll for worker's comp premiums, their counterpart with an EMR of 1.50 would be paying $\$ 48$ per $\$ 100$ of payroll (1.5 x $\$ 32=\$ 48)$ or $\$ 16$ per $\$ 100$ more. Similarly, a safe contractor with an EMR of 0.70 would pay $\$ 22.40$ per $\$ 100$ of payroll or approximately $47 \%$ that of the EMR 1.50 contractor. Worker's compensation premiums paid by the contractor will thus be based on the rate for the particular trade adjusted by the EMR and other discounts or credits. The premiums obviously include overhead and profit for the particular carrier or administrative costs when the state is the carrier. Given the substantial amounts of labor involved in most construction projects, worker's comp costs are by far the most expensive insurance coverage for most contractors in commercial or heavy construction segments dwarfing the costs of other insurance coverage. This analysis also points to the fact that a contractor with a favorable EMR has a significant competitive advantage in bidding projects over their competition with unfavorable EMRs.

A newly-formed contractor starts out with a 1.00 EMR. The EMR then gets adjusted upwards or downwards on a three-year rolling average based on the contractor's safety record. Even if a contractor has better than average safety performance in a single year, the other two years of safety performance have to be averaged in to this number. ${ }^{3}$ Confidential examination by one of the authors a few years ago of one carrier's EMR ratings for contractors found the lowest EMR for a contractor at a 0.58 and the highest contractor EMR at 1.74 for a spread of $1.16 .{ }^{2}$ Notably contractors with high EMRs also had high rates of business failure based on discussions with the carrier. $^{2}$

Evaluate Management And Supervision On Safety Performance 
An adage in management is that which gets measured gets attention by those being measured on the item. Since safety performance has a large role in worker's compensation costs, contractors need to incorporate this metric into their performance evaluation process. As a base, it is expected that firms looking to improve their safety performance will ensure that workers are adequately trained in the particulars related to safe on-the-job practices. However, both supervision and management should be should as part of their evaluation have safety included in this evaluation. This benchmarking of safety performance though should not set up perverse incentives that can potentially create safety problems later on for the firm. One of the best ways to evaluate safety performance is by rewarding safe behaviors on a jobsite. Similarly unsafe behaviors should detract from safety evaluations. If a worker is observed to be properly using personnel protective equipment such as a fall protection harness, this would be marked as a credit to the project team. On the other hand, if a worker is observed to be performing metal cutting without safety glasses and face shield, this negative behavior example would be a debit to the project team. The problem with other types of safety evaluations is that they can result in a perverse incentive as noted above. If a supervisor is rewarded for no accidents taking place within a given time period the supervisor has the perverse incentive to not report accidents. Or they may cover up an accident or attempt to categorize a serious accident as a non-serious incident. Another problem is that left untreated or not properly treated, a small accident such as a cut hand may turn into a major problem if it becomes infected thereby requiring surgery. Therefore behavior-based safety incentives have been regarded as the best type of incentives when rewarding safety performance on a project.

The reward for a high percentage of sound safety behaviors on a project should be significant enough to be an important part of the compensation for supervisors and managers. If the project team is overwhelmingly rewarded for project metrics as production, quality, cost and schedule to the point where safety rewards are minimal then safety will typically be ignored by the team. Safety because of its impact on the worker's compensation cost structure should be reflected in the reward system. Another aspect of this is to select the project team based on their ratings as to enforcing safety behavior on projects. The problem here is that it is easier to measure metrics such as cost and schedule because the systems for their measurement is already in place. Systems for safety behavior measurement are not. This also brings up the age-old question of "who guards the guards?" If safety personnel performing the rating of safety behaviors report directly to project management, there is the potential for corruption of this rating method. Instead safety personnel performing these ratings should report higher up the organizational chart rather than directly to project management.

\section{Management and Supervisory Safety Education}

Contractor personnel should have effective training in safe practices. Safe practices should include items such as engineering controls and management controls to eliminate hazards. Techniques such as pre-fab work in a shop provide a controlled environment with built-in safety advantages. Work pre-fabricated in the field at ground level provides workers with a safer environment in this instance as well. Other engineering controls can eliminate hazardous substances such as toxic cleaning compounds in favor of those with no or minimal impact on worker health. Items such as these can impact worker's comp experience. One key element lacking is understanding on the part of project supervisory and management personnel as to their 
potential impact on worker's compensation costs. A key problem is that supervision and management in construction have little or no understanding as to how worker's compensation costs especially with regard to EMRs are determined by carriers. Given this fact, it behooves contractors to implement training that will include this knowledge.

Accurate Contractor Employee Classification

Field personnel must continually ensure that workers are correctly classified as to job functions over the course of a project. As an example, from R.S. Means Building Construction Cost Data, an ironworker in California on structural steel erection has a premium of $\$ 32.53$ per $\$ 100$ of base labor payroll but place that same person on interior work and the premium drops to $\$ 16.42$ per $\$ 100$ or $50 \%$ of the higher premium. ${ }^{13}$ With this worker on a forty-hour week at a base wage rate of $\$ 50.50$, incorrect classification at the higher rate costs the contractor an extra $\$ 325.43$ per worker $(\$ 50.50 /$ hour x 40 hours $=\$ 2020 ; \$ 657.11-\$ 331.68=\$ 325.43)$. Given the substantial dollar amounts involved, field personnel should be instructed to continually monitor these metrics to ensure accurate classification. A more subtle distinction is within a crew as to what type of work is being performed by which workers in the crew. A four-person crew installing pipe within a trench in a trench box may have all four workers be classified as working in the trench at the high rate for that activity. But if one of the four workers is a ground person up on the bank, then that person's work should be separately broken out and have worker's compensation premiums paid at the lower applicable rate. Over the course of a year these proper classification techniques can save substantial costs for the contractor.

\section{Accurate Contractor Classification}

Contractors can be the victim of improper premium classifications because their name may be similar to that of another contractor. As a hypothetical, XYZ Contracting who is a safe contractor may have their EMR rating confused for that of XYZ Construction who is an unsafe contractor. Or one contractor's severe accident may be charged to the record of the wrong contractor. Unfortunately some of the coding that takes place inside insurance carriers or state agencies is entry-level work given to the lowest common denominator of employee. ${ }^{2}$ Contractors need to talk with their carrier for exact explanations of the determination of their premium rates including EMR calculations. With thousands of contractors present in larger states, including many with similar names, these confusions unfortunately happen from time to time.

\section{Job Safety Analysis}

Two decades ago, one of the authors worked for several years in the construction division of a large manufacturer. The corporate safety policy for that manufacturer was that before any work package took place a job safety analysis (JSA) was required beforehand. ${ }^{11}$ The JSA would then be reviewed prior to work start by the area manager for methodology and completeness. Without an approved JSA no work could take place. At first, this author viewed the JSA requirement as just more paperwork. Once accustomed to doing these JSAs, it quickly became apparent that this was a very useful element of the safety program. A subsidiary benefit was that in planning 
for safety it also forced one to better plan for the work package itself. Therefore there was not only a safety benefit but a productivity benefit as well.

In discussions with safety-conscious contractors in the years since then this author has been struck by how many of those contractors follow this same practice of mandatory pre-job JSAs attached to their work packages.

\section{Mandatory Substance Abuse Testing}

Numerous contractors over the years have implemented requirements for substance abuse testing for their employees on either a pre-job basis, randomly, or on a post-accident basis. In many states, worker's compensation coverage can be denied an employee if they are found post accident to be negatively affected with substance abuse issues. On a large hotel project, discussions with the unionized managing general contractor found that they utilized pre-job substance abuse testing. This was publicized at the union hiring hall prior to workers being referred to this contractor. The contractor was self-performing concrete work on the project and therefore had laborers, carpenters, ironworkers, and cement finishers on their payroll. Between these four trades, they were rejecting $40 \%$ of the hiring hall referrals who could not pass their six-drug screening test. ${ }^{4}$ Needless to say this was surprising to hear numbers were this high and also that these workers were informed prior to this at the hiring hall that they would be tested at the job site when they went there. Discussions with other contractors since then in the same geographic locale have revealed numbers in this same range. ${ }^{4}$

The U.S. Department of Labor in their study of full-time workers aged 18-64 in industries across the U.S. found in their results that $13.7 \%$ of construction workers engaged in illicit drug use and $15.9 \%$ of construction workers had heavy alcohol dependence. ${ }^{5}$ These figures for construction workers were approximately twice as high as the averages for all industries. ${ }^{5}$

The substance abuse issue has two components with an affected worker injuring themselves or the affected worker injuring other workers through their unsafe actions. Discussions with contractors over the years that have implemented substance abuse testing on a pre-hire basis found that their insurance costs in this area experienced decreases along with improved safety performance.

Subcontractor Selection Practices

The construction industry is a subcontractor-driven industry. Decades ago, the typical general contractor on building construction work would subcontract out only a few specialty areas such as mechanical and electrical work. Today's general contractors sub out increasing percentages of work such that a general contractor may be doing $30 \%$ of less of the project with their own forces. General contractors in the heavy construction segment are typically the notable exceptions to these high percentages of subcontracted work. Subcontractors in certain areas have followed the lead of general contractors with their own utilization of third and fourth tier sub-subcontractors to complete their work packages. Given the ever-present subcontractors controlling major portions of the work on projects and their impact on safety, it only makes sense that general contractors, construction managers and others should examine subcontractor safety 
records as part of their selection criteria. It was noted elsewhere in this paper that more astute owners have utilized EMR criteria with ceilings at 0.80 or 0.90 as examples to screen out contractors with poorer safety records. The poor safety practices of subcontractors and subsubcontractors can have a direct impact on the safety performance of general contractor's and other workforces. General contractors and construction managers on bid work need to make the case to owners to incorporate these types of safety criteria within their specifications and other selection criteria.

Safe contractors do not want to be adversely impacted by unsafe contractors on a construction project. Safe subcontractors want to work beside other safe subcontractors. General contractors and construction managers should feel the same way. Subcontractors have no control over the selection of other subs on a project save for their own retention of sub-subcontractors. General contractors and construction managers should set this criteria wherever and whenever they can to exercise effective control.

Even with general contractors or construction managers (GC/CM), many owners reserve the right such as in contract forms to bring their own contractors onto a project for certain specialty work. GCs/CMs should make their case to owners to incorporate EMR selection criteria such as with an EMR 0.80 ceiling so that everyone is on a level playing field and unsafe contractors do not populate the project.

\section{Mandatory Pre-Shift Exercise Sessions}

Some construction owners have implemented specification requirements on their projects requiring all workers to perform stretching and flexibility exercises prior to beginning work on the shift. This practice comes from Japan where a wide range of firms ranging from service, retail, construction to manufacturing have successful implemented these pre-shift exercise sessions. These sessions have been held to result in less injuries over time particularly with regard to soft tissue injuries. Japanese-transplant firms have implemented these practices in their U.S. plants for both the construction and operation of these facilities. While some may mock these practices, the Japanese in very methodical fashion have found that these practices are cost effective and reduce certain types of accidents.

This idea for pre-shift exercise sessions has been adopted by certain other firms here in the U.S. for their construction projects. ${ }^{6}$ Certainly it is an idea with promise to be tried out on projects based on its past record of success.

\section{Owner's Impact On Safety}

Owners can have a significant impact on safety and thereby worker's compensation costs. Just as with management and supervision measured on safety performance by their contractors so too can owners measure their selected contractors on safety. Safe contractors as defined with an EMR better than that in the 0.80 to 0.90 range have not achieved this record without hard work. Owners may break projects up into various elements with multiple primes or separate trade contracts depending on contracting method. Because of the interdependent nature of contractor relationships on construction projects, a safe contractor can be negatively impacted by the unsafe 
activities performed by an unsafe contractor. As an example, on a large hotel project, the structural steel contractor (a multiple prime) took down handrail and improperly reinstalled it. A person for another contractor on the project contacted this same handrail and fell to his death when the handrail gave way. Safe contractors should encourage owners to select other safe contractors for their work.

One of the ready criteria for an owner in selecting safe contractors is that of the experience modification rating (EMR). As aforementioned in the section on subcontractor selection, owner incorporation of EMR target values within the project specifications ensures that all contractors are competing on a level playing field. There are some owners that include specification requirements stating that the average age of a contractor's jobsite equipment on the project can not exceed ten years. ${ }^{7}$ The thought here is that newer equipment will automatically have enhanced safety features.

Other techniques that owners can implement are mandatory requirements for safety personnel on projects and mandatory safety training. The Army Corps of Engineers and Naval Facilities Engineering Command mandate that all contractor personnel working on their governmental projects be safety trained per their EM-385 Safety Manual. ${ }^{8}$ The EM-385 Safety Class is 40 hours in length. ${ }^{8}$ Other owners have mandated ratios of one full-time safety person per so many workers on their projects. ${ }^{9}$

Certain owners compensate contractors for safety equipment such as barricades and warning signs on projects on a cost-plus basis. An example of this is as below in Table 2 excerpted from the State of Nevada Department of Transportation's specifications regarding road and bridge construction: ${ }^{10}$

624.05.01 Payment.

Table 2

\begin{tabular}{|l|l|}
\hline Payment will be made under: & \\
\hline Detours & Appropriate Bid Items or Force Account \\
\hline Flagger & Hour \\
\hline Uniformed Traffic Control Officer & Force Account \\
\hline Traffic Control Supervisor & Day \\
\hline Pilot Car & Hour \\
\hline Rent Equipment (type) & Hour \\
\hline
\end{tabular}

The advantage of practices such as the above is that there is no incentive for the contractor to cut corners when it comes to safety on the project. Work zone safety certainly protects the public but past analysis of statistics finds that construction workers in work zones have the highest injury and fatality rates. ${ }^{8}$

There are humanitarian reasons why owners should encourage the hiring of safer contractors for their projects. These safer contractors because of their favorable EMRs will save the owner money. In addition, owners with safer jobsites will not encounter unfavorable publicity that is part and parcel of unsafe projects. Fatalities and disabling injuries on project sites can also involve owners in third-party lawsuits. Therefore there are a variety of reasons why owners and contractors should forge a partnership to promote safety on their projects. 
On larger projects, workers compensation costs can be reduced through entity-controlled insurance policies (ECIPs). These ECIPs may also be referred to as Owner-Controlled Insurance Policies (OCIPs) or as Contractor-Controlled Insurance Policies (CCIPs) depending on which entity is the controlling party. ECIPs can be utilized for all the insurance on a project or for selected insurance elements. A key benefit with an ECIP is the economies of scale that result since single insurance policies do not have to be purchased by every contractor on a job. Coverage can be unified with no gaps and no overlaps which are problematic with a plethora of individual policies on jobs. ECIPs eliminate the need to audit contractors on the project to ascertain whether they have and/or are maintaining their insurance coverage.

A key area for ECIPs is the coverage for worker's compensation insurance. An ECIP leads to uniform safety practices and safety control on a jobsite. The ECIP is also the ideal vehicle to produce savings in worker's compensation costs. A large industrial owner with a favorable EMR may assume costs for all worker's comp premiums on a large project as a limited ECIP just for worker's comp. They then place all contractors under their unified safety command. In order for an ECIP to be successful in the safety area, one author has recommended a safety program with the following elements: ${ }^{12}$

- $\quad$ "A formal, structured program with a written safety manual

- Contractor and subcontractor safety prequalification procedures

- Safety training, monitoring, and periodic "toolbox" talks

- Independent, scheduled and unscheduled safety audits

- A full-time safety representative and onsite safety staffing

- Pre-mobilization safety orientation and certification process

- Drug and alcohol testing programs"

\section{Conclusion}

The topics discussed in this paper can be incorporated into a variety of construction classes including those covering topics involving estimating, safety, and project/firm management. Professors in estimating can show the impact on competitive bidding between contractors with industry-average EMRs versus those with improved EMRs. Professors can also illustrate the impact on overall labor costs in high-impact construction trades for worker's compensation premiums. Those teaching construction safety topics should note that not only is adherence to safety requirements a regulatory mandate under federal OSHA and other state requirements but that sound safety practice in the field has a significant impact on the contractor's competitive position. The same would apply to coursework in project management where an emphasis on sound safety performance can be shown to be just as important to a firm's long-term health as other metrics of schedule, cost, and quality. With a three-year rolling average for calculations involving a contractor's EMR, poor safety performance in one year from one project impacts that contractor not only in that year but into the future. Students should appreciate that a safety shortcut resulting in a single or multiple fatalities or disabling injuries for a short-term gain has significant impacts on the contractor's future competitive position. 
Students need to understand that there are a number of techniques that contractors can implement to effect substantial savings in their worker's compensation cost structure. Worker's comp costs are a significant cost of doing business for most contractors. Many supervisors and managers in construction along with newly-minted students do not understand that they can have a substantial impact in this area. Contractors need to continually audit their worker classifications on projects to ensure they are paying correct rates. Moreover they need to ensure that their overall EMR actually represents that of their own firm and not a similarly-named entity which can yield significant cost differences. Through substance-abuse testing, contractors can screen out potential problem employees. Pre-job safety planning for all work packages through job safety analysis can lead to not only safer worksites but this planning also produces better job results. Because of the interdependence on jobsites and the impact on safety, owners, general contractors, construction managers, and subcontractors need to select their partners with a view towards safe performance by these partners. The key selection criteria is EMR. Owners ultimately are the key driver for better safety resulting in lower worker comp costs on their projects. Owners through specifications can force the selection of safer contractors and can compensate contractors for their safety efforts thereby eliminating incentives to cut safety corners. Entitycontrolled insurance policies tailored for larger projects with unified safety practices can produce substantial savings on this cost structure. Construction graduates who go to work for other entities besides contractors such as owners and developers should realize that they can influence safety through specifications that set EMR requirements and other selection techniques. Construction education should emphasize that improved safety means lower costs which yields better value for the industry and owners/developers who are the construction consumers.

\section{References}

1.) Broderick, T. (2004). Introduction to Construction Safety p. 3 in Hill, D. Construction Safety Management And Engineering, ASSE, Des Plaines, IL.

2.) Opfer, N. (2010) Unpublished Study Of One Carrier's Experience On Contractor's Worker's Compensation EMRs.

3.) Hill, D. (2004). High Costs of Worker Injuries in Construction pp. 67-77 in Hill, D. Construction Safety Management And Engineering, ASSE, Des Plaines, IL.

4.) Opfer, N. (2007) Contractor Discussions On Substance Abuse Testing in Las Vegas, Nevada.

5.) (2012) Zero Tolerance: Illicit Drug And Alcohol Use In The Construction Industry at http://precast.org/2012/10/zero-tolerance-illicit-drug-and-alcohol-use-in-the-construction-industry/ (Site accessed December 4, 2013).

6.) Lancaster CA. (2013) First Solar Antelope Valley Solar Ranch Project: Phase 1 \& 2 Project Specifications, 7.) (1986) Shell Oil and Monsanto Corp. Project Specifications Review. KDM Associates. St. Louis MO.

8.) Stakes, V. (2012) Military EM-385 OSHA Safety Class. University of California, San Diego OSHA Training Institute, San Diego, CA.

9.) (2005) Project Specifications, MGM City Center Las Vegas, NV. 
10.) (2001) State Of Nevada Department Of Transportation Standard Specifications for Road and Bridge Construction.

11.) (1981) Inland Steel Corp. Safety Manual. Inland Steel Corp. E. Chicago, IN.

12.) Greiner, D. (2001) Implementing an Owner-Controlled Insurance Program at http://www.expertlaw.com/library/business/ocip-implementation.html (Site accessed December 11, 2013).

13.) Waier, P. (2013) Workers' Compensation Insurance Rates by States pp. 796-798 in

R.S. Means Building Construction Cost Data 2014, 72nd Edition. R.S. Means, Norwell, MA. 